See Article page $\mathrm{XXX}$.

\section{Commentary: At the surgeon's discretion: Complete revascularization is best}

\author{
J. Hunter Mehaffey, MD, MSc, and \\ Robert B. Hawkins, MD, MSc
}

Bianco and colleagues ${ }^{1}$ present an inverse probability of treatment weighted study of long-term outcomes after coronary artery bypass grafting (CABG) in patients undergoing complete versus incomplete revascularization. The authors define completeness of revascularization as number of vessels or territories meeting criteria for stenosis by the interventional cardiology team that were or were not revascularized. A secondary analysis was performed to assess the relationships among main-branch (ie, left main, left anterior descending, circumflex, and right coronary artery) versus nonmain-branch completeness of revascularization. The primary end point was major cardiac and cerebrovascular events or mortality evaluated by medical records, telephone/e-mail follow-up, and the Social Security Death Index. The authors conclude complete surgical revascularization is associated with improved midterm survival and reduced major adverse events in the main-branch subset.

Completeness of revascularization has been demonstrated to be strongly associated with 10-year survival after percutaneous coronary intervention. ${ }^{2}$ Furthermore, Garcia and colleges ${ }^{3}$ highlight that complete revascularization is achieved more commonly with $\mathrm{CABG}$ than with percutaneous coronary intervention. A post hoc analysis of the Veterans Affairs Randomized On/Off Bypass (ROOBY) trial demonstrated that incomplete revascularization (by follow-up angiography at 1 year) was associated with higher major cardiac and cerebrovascular events but not

\footnotetext{
From the Division of Thoracic and Cardiovascular Surgery, University of Virginia, Charlottesville, Va.

Disclosures: The authors reported no conflicts of interest.

The Journal policy requires editors and reviewers to disclose conflicts of interest and to decline handling or reviewing manuscripts for which they may have a conflict of interest. The editors and reviewers of this article have no conflicts of interest.

Received for publication July 7, 2021; revisions received July 7, 2021; accepted for publication July 7, 2021.

Address for reprints: J. Hunter Mehaffey, MD, MSc, Department of Thoracic and Cardiovascular Surgery, University of Virginia, PO Box 800679, Charlottesville, VA 22908-0709 (E-mail: jhm9t@ virginia.edu).

J Thorac Cardiovasc Surg 2021; $\mathbf{\square}: 1-2$

$0022-5223 / \$ 36.00$

Copyright (c) 2021 by The American Association for Thoracic Surgery

https://doi.org/10.1016/j.jtcvs.2021.07.008
}

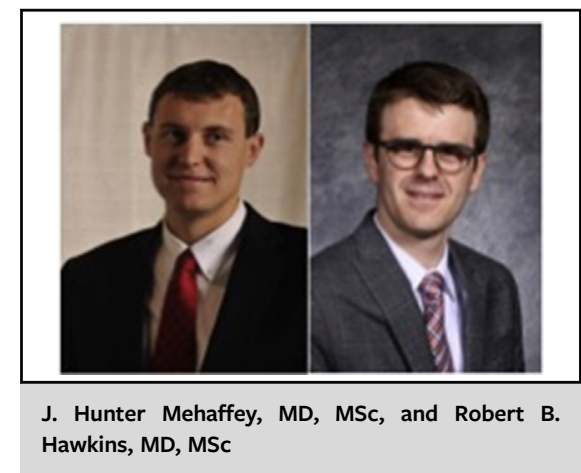

CENTRAL MESSAGE

Complete revascularization in CABG may be associated with better midterm outcomes in a retrospective IPTW study; however, accounting for selection bias and surgical decision making is difficult.

mortality. ${ }^{4}$ However, the benefit of complete revascularization in patients undergoing CABG is more controversial because some studies suggest no advantage and possible detrimental effects of prolonged bypass time in older or higher risk patients. ${ }^{5}$ Finally, a recent study by Rosenblum and colleagues ${ }^{6}$ demonstrated multiple arterial CABG provides a modest midterm survival benefit over single-arterial CABG, regardless of completeness of revascularization. ${ }^{6}$

Given this landscape, Bianco and colleagues ${ }^{1}$ investigate a population of isolated CABG with no exclusion based on age, ejection fraction, or predicted risk. The groups are well balanced based on available data variables; however, the retrospective design introduces significant bias from the surgical decision making dictating completeness of revascularization. Unfortunately, we are unable to determine whether or not complete revascularization simply selects patients with good targets and adequate conduit, whereas those who were not completely revascularized did not have targets or had poor conduit options. Therefore, the disparity in outcomes could be explained by the difference in patients, which cannot be assessed retrospectively in this database study. Whereas the authors are to be commended on this robust analysis and rigorous statistical approach the clinical message is familiar: Complete revascularization is best as long as it is safe and feasible. The secondary analysis does provide additional support to the notion of a 
territory- or main-branch-vessel-driven approach to complete revascularization rather than an all-vessel definition.

\section{References}

1. Bianco V, Kilic A, Aranda-Michel E, Serna-Gallegos D, Ferdinand F, DunnLewis $\mathrm{C}$, et al. Complete revascularization during coronary artery bypass grafting is associated with reduced major adverse events. J Thorac Cardiovasc Surg. 2021. XXX:XXX.

2. Vieira RD, Hueb W, Gersh BJ, Lima EG, Pereira AC, Rezende PC, et al. Effect of complete revascularization on 10-year survival of patients with stable multivessel coronary artery disease: MASS II trial. Circulation. 2012;126: S158-63.
3. Garcia S, Sandoval Y, Roukoz H, Adabag S, Canoniero M, Yannopoulos D, et al. Outcomes after complete versus incomplete revascularization of patients with multivessel coronary artery disease: a meta-analysis of 89,883 patients enrolled in randomized clinical trials and observational studies. J Am Coll Cardiol. 2013; 62:1421-31.

4. Hattler B, Grover FL, Wagner T, Hawkins RB, Quin JA, Collins JF, et al. Incidence and prognostic impact of incomplete revascularization documented by coronary angiography 1 year after coronary artery bypass grafting. Am J Cardiol. 2020; 131:7-11.

5. Girerd N, Magne J, Rabilloud M, Charbonneau E, Mohamadi S, Pibarot P, et al. The impact of complete revascularization on long-term survival is strongly dependent on age. Ann Thorac Surg. 2012;94:1166-72.

6. Rosenblum JM, Binongo J, Wei J, Liu Y, Leshnower BG, Chen EP, et al. Priorities in coronary artery bypass grafting: is midterm survival more dependent on completeness of revascularization or multiple arterial grafts? J Thorac Cardiovasc Surg. 2021;161:2070-8.e2076. 